\title{
Toxicity of prirmiphos-methyl and three essential oils, alone and in combination against Callosobruchus maculatus (Fab.)
}

M. Khalequzzaman and Sadia Nazneen Rumu

Department of Zoology, University of Rajshahi, Rajshahi 6205, Bangladesh

\begin{abstract}
Toxicity of pirimiphos-methyl and three essential oils, viz. cardamom [Elettaria cardamomum (L.) Maton.], cinnamon (Cinnamomum aromaticum Nees) and clove [Syzygium aromaticum (L.) Merr. \& Perry]; either singly or in mixture in different ratios were investigated on the cowpea weevil, Callosobruchus maculatus (F.) adults, through residual film bioassay. The $L_{50}$ of pirimiphos-methyl was $0.011 \mu \mathrm{g} \mathrm{cm}^{-2}$ and that of cardamom, cinnamon and clove oils were 20.68, 12.38 and $16.89 \mu \mathrm{g} \mathrm{cm}^{-2}$ respectively after $24 \mathrm{~h}$ post-treatment. Pirimiphos-methyl and tested essential oils were used as mixture of $1: 1,1: 2,1: 5,1: 10$ and 1:20 and the $L_{50}$ values were calculated. All essential oils when combined with pirimiphos-methyl proved to be antagonistic effect against C. maculatus adults except cardamom oil which offered synergistic effect at the 1:20 ratio with pirimiphos-methyl.
\end{abstract}

Key words: pirimiphos-methyl, cardamom, cinnamon, clove, LD 50 , synergism.

\section{Introduction}

Essential oils are also called volatile or ethereal oils (Guenther, 1948), derived mostly from vegetable sources, occur as a rule, in small concentrations in special cells of plant and distributed or distributed over many particular parts, e.g., leaves (citronella, eucalyptus), barks (cinnamon), roots, rhizomes (turmeric, ginger, galangal), flowers (bergamot tree and tuberose), fruits (all spice, anise, star anise) or seeds (nutmeg). They are volatile and can act like fumigants offering the prospect for use in storedproduct protection (Huang et al., 2000; Lee et al., 2004), contact insecticides (Ngamo et al., 2007), antifeedent or repellent effects (Park et al., 2003; García et al., 2005) and may also affect some biological parameters such as growth rate, life span and reproduction (Raja \& William, 2008). The toxicity of a large number of essential oils and their constituents has been evaluated against a number of stored product insects (Asawalam, 2006; Chaubey, 2008).

Cardamom spice consisting of whole or ground dried fruit, or seeds, of Elettaria cardamomum (L.) Maton. an herbaceous perennial of the family Zingiberaceae. A perennial, reed-like herb, cardamom grows wild and is cultivated in India and Ceylon. The essential oil occurs in large parenchyma cells underlying the epidermis of the seed coat. Oil is extracted from the fruits is used both in pharmacy and perfumery. Its main constituents are 1,8-cineole (eucalyptol) and alpha-terpinyl acetate. Cinnamon (Cinnamomum aromaticum Nees) is a bushy evergreen tree of the family Lauraceae, native to Sri Lanka, India, and Myanmar and also cultivated in South America and the West Indies. The most abundant component in the stem bark oil is 1,8-cineole, which constitutes $30 \%$ of the oil. p-Cymene (20.7\%), linalool (13,7\%), $\alpha$-terpineol (5.1\%) and terpinen-4-ol (2.9\%) were among the major constituents identified (Ali \& Jantan, 1999). The clove tree [Syzygium aromaticum (L.) Merr. \& Perry] is endemic in the North Moluccas (Indonesia) and was of old cultivated in the islands of Termate, Tidore, Bacan and the West coast of Hamahera. The Dutch extended cultivation to several other islands in the Moluccas, but only after the end of the Dutch monopoly (18th Century), clove trees were introduced to other countries. The oil itself is dominated by eugenol (70 to 85\%), eugenol acetate (15\%) and $\beta$-caryophyllene (5 to $12 \%$ ), which together make up $99 \%$ of the oil (Bauer et al., 2001). Pirimiphos-methyl (Actellic), an organophosphate, registered in the USA for treating stored corn and sorghum (USEPA, 2003) has lower mammalian toxicity showed to be effective on wheat against several stored-product insects (Huang \& Subramanyam, 2005).

Callosobruchus species are major pests of stored grains and grain products in the tropics (Prevett, 1961). Over $90 \%$ of the insect damage to cowpea seeds is caused by Callosobruchus maculatus (F.) (Caswell, 1981). The insect lays its eggs on the seeds of cowpea, which hatch and produced 
larvae that bore into the seed cotyledons on which they feed (Onuh \& Onyenekwe, 2008). Infestation may reach $100 \%$ within 3-5 months of storage (Braga et al., 2007). Control of C. maculatus relies heavily on the use of synthetic insecticides and fumigants, which has led to problems such as disturbances of the environment, increasing costs of application, pest resurgence, pest resistance to pesticides and lethal effects on non-target organisms in addition to direct toxicity to users. The present study was to investigate the effect of pirimiphos-methyl and essential oils applied singly or combined in simple mixtures on adult C. maculatus.

\section{Materials and Methods}

Test insect and essential oils: C. maculatus from the groceries of Shaheb Bazar, Rajshahi. The cowpea, Vigna unguiculata (L.) Walp. seeds were used as food medium throughout the experiments. The essential oils, cardamom, cinnamon and clove were purchased as pure oil (India) from an essential oil shop. The oils were further dehydrated in a vacuum rotary evaporator. The oils were then collected in sealed glass containers and refrigerated in the dark at $4^{\circ} \mathrm{C}$ until they are used.

Toxicity tests with single dose: Residual film method (Busvine, 1971) was used to test the mortality of the adult $C$. maculatus. Technical grade of Pirimiphos-methyl (0-2-(diethylamino)-6methylpyrimidin-4-yl) 0,0-dimethyl phosphorothioate (C.A.) 0-[2-(diethylamino)-6-methyl-4-pyrimidinyl] 0 , 0-dimethyl phosphorothioate) was used as insecticide, collected from $\mathrm{ACl}$ Limited. The insecticide was diluted in acetone and different doses were prepared. At first an ad-hoc experiment was made. After having a clear picture about mortality of beetles, the final experiments were set up. The doses used for pirimiphos methyl were $0.047,0.037,0.028,0.019$ and 0.009 $\mu \mathrm{g} \mathrm{cm}{ }^{-2}$, whereas the doses of cardamom, cinnamon and clove oils were 56.586, 47.155, $37.724,28.293$ and $18.862 \mu \mathrm{g} \mathrm{cm}{ }^{-2}, 37.724$, $31.436,25.149,18.862$ and $12.575 \mu \mathrm{g} \mathrm{cm}^{-2}$, and $47.155,39.296,31.436,23.575$ and $15.718 \mu \mathrm{g}$ $\mathrm{cm}^{-2}$ respectively. One $\mathrm{ml}$ of liquid from each dose was dropped on petri dishes $(90 \mathrm{~mm})$ separately, covering uniformly the whole area of the petri dish. They were then kept open for sometimes to dry-up. Four plastic rings $(30 \mathrm{~mm})$ were placed inside a petri dish and 10 adult beetles were released within each ring. The rings within the petri dish were served as replications. The doses were calculated by measuring the actual amount of active ingredient $(\mu \mathrm{g})$ present in one $\mathrm{ml}$ of the solvent divided by the surface area of the petri dish. One batch of control was maintained in which only acetone was applied for each strains, respectively.

Toxicity tests with combined doses: Pirimiphosmethyl was combined in mass ratios (1:1, 1:2, 1:5, 1:10 and 1:20) with the essential oils used and applied on C. maculatus adults. The doses of pirimiphis-methyl and cardamom oil in mass ratios were $0.051,0.041,0.031,0.021$ and $0.011 \mu \mathrm{g} \mathrm{cm}^{-}$

${ }^{2}$ for $1: 1$ ratio; $0.099,0.079,0.059,0.039$ and $0.019 \mu \mathrm{g} \mathrm{cm}^{-2}$ for 1.2 ratio; $1.202,0.962,0.721$, 0.481 and $0.240 \mu \mathrm{g} \mathrm{cm}^{-2}$ for $1: 5$ ratio; 1.587, $1.270,0.952,0.634$ and $0.317 \mu \mathrm{g} \mathrm{cm}^{-2}$ for $1: 10$ ratio and $0.790,0.632,0.474,0.316$ and $0.158 \mu \mathrm{g}$ $\mathrm{cm}^{-2} \mu \mathrm{g} \mathrm{cm}^{-2}$ for 1:20 ratio. In case of pirimiphos and cinnamon oil the combined doses were 0.130 , $0.104,0.078,0.052$ and $0.026 \mu \mathrm{g} \mathrm{cm}^{-2}$ for $1: 1$ ratio; 0.247, 0.198, 0.148, 0.099 and $0.049 \mu \mathrm{g} \mathrm{cm}^{-}$ 2 for 1.2 ratio; $10.601,0.481,0.361,0.240$ and $0.120 \mu \mathrm{g} \mathrm{cm}^{-2}$ for 1.5 ratio; $10.798,0.638,0.479$, 0.317 and $0.159 \mu \mathrm{g} \mathrm{cm}^{-2}$ for $1: 10$ ratio and 0.790 , $0.632,0.474,0.316$ and $0.164 \mu \mathrm{g} \mathrm{cm}^{-2}$ for $1: 20$ ratio. The doses of pirimiphos-methyl and clove oil in mass ratios were $0.108,0.086,0.065,0.043$ and $0.022 \mu \mathrm{g} \mathrm{cm}^{-2}$ for 1:1 ratio; 0.206, 0.165, $0.123,0.082$ and $0.041 \mu \mathrm{g} \mathrm{cm}^{-2}$ for 1.2 ratio; $0.250,0.200,0.150,0.100$ and $0.050 \mu \mathrm{g} \mathrm{cm}^{-2}$ for $1: 5$ ratio; $1.588,1.270,0.953,0.635$ and $0.317 \mu \mathrm{g}$ $\mathrm{cm}^{-2}$ for $1: 10$ ratio and $2.369,1.896,1.422,0.948$ and $0.474 \mu \mathrm{g} \mathrm{cm}^{-2}$ for $1: 20$ ratio.

Analysis of Data: The mortality of adult beetles was recorded after $24 \mathrm{~h}$ of treatment. Corrected mortality percentage was calculated using Abbott's formula (Abbott, 1925); probit analysis was done according to Finney (1947) using a software developed in the Department of Agricultural and Environmental Science, University of Newcastle upon Tyne, UK. If the probability was greater than $5 \%$ an automatic correction of heterogeneity was introduced. Cotoxicity coefficient was calculated as for Sun \& Johnson (1960).

\section{Results}

Single bioassay: The $\mathrm{LD}_{50}$ of pirimiphos-methyl has been calculated as $0.011 \mu \mathrm{g} \mathrm{cm}^{-2}$ with the $95 \%$ confidence limits was 0.007 to $0.017 \mu \mathrm{g} \mathrm{cm}^{-2}$. The $\mathrm{LD}_{50}$ of cardamom, cinnamon and clove oil was $20.68,12.38$ and $16.89 \mu \mathrm{g} \mathrm{cm}^{-2}$ respectively with the 
$95 \%$ confidence limits were 15.90 to $26.90,8.65$ to 17.73 and 12.98 to $21.97 \mu \mathrm{g} \mathrm{cm}^{-2}$ respectively. The regression lines are presented in Fig.1.

Combined bioassay: Pirimiphos-methyl and cardamom oil was used as mixture of 1:1, 1:2, $1: 5,1: 10$ and $1: 20$ and the $L_{50}$ was $0.027,0.048$,
$0.393,0.418$ and $0.201 \mu \mathrm{g} \mathrm{cm}^{-2}$ respectively. In the same ratios of pirimiphos-methyl and cinnamon oil the $\mathrm{LD}_{50}$ was $0.079,0.140,0.327,0.241$ and 0.294 $\mu \mathrm{g} \mathrm{cm}^{-2}$; and pirimiphos-methyl and clove oil the $\mathrm{LD}_{50}$ was $0.077,0.086,0.100,0.488$ and $0.661 \mu \mathrm{g}$ $\mathrm{cm}^{-2}$ (Table 1).

Table 1. $L D_{50}$, regression equation, co-toxicity coefficient and synergistic ratio due to the effect of pirimiphos-methyl and different essential oil mixtures on adult $C$. maculatus after 24 hours of treatment.

\begin{tabular}{|c|c|c|c|c|c|c|c|c|}
\hline$\overline{\text { Mixture }}$ & Ratio & $\begin{array}{c}\text { LD 50 } \\
\left(\mu \mathrm{g} \mathrm{cm}^{-2}\right)\end{array}$ & $\begin{array}{r}95 \% \text { confic } \\
\text { Lower }\left(\mu \mathrm{g} \mathrm{cm}^{-2}\right)\end{array}$ & $\begin{array}{l}\text { idence limits } \\
\text { Upper }\left(\mu \mathrm{g} \mathrm{cm}^{-2}\right)\end{array}$ & Regression equations & $\begin{array}{c}\chi^{2} \\
(3 \mathrm{df})\end{array}$ & $\begin{array}{l}\text { Cotoxicity } \\
\text { coefficient }\end{array}$ & $\begin{array}{c}\text { Synergistic } \\
\text { ratio }\end{array}$ \\
\hline & $1: 1$ & 0.027 & 0.020 & 0.037 & $Y=4.418004 \pm 1.348146 \mathrm{X}$ & 0.61 & 84.44 & 0.422 \\
\hline & $1: 2$ & 0.048 & 0.035 & 0.066 & $Y=4.120276 \pm 1.292739 x$ & 0.81 & 71.70 & 0.239 \\
\hline \multirow[t]{5}{*}{ PM:CA } & $1: 5$ & 0.393 & 0.251 & 0.614 & $Y=4.302636 \pm 1.173538 X$ & 0.76 & 17.40 & 0.029 \\
\hline & 1:10 & 0.418 & 0.252 & 0.694 & $Y=4.228422 \pm 1.242516 \mathrm{X}$ & 1.66 & 30.08 & 0.027 \\
\hline & $1: 20$ & 0.201 & 0.112 & 0.358 & $Y=4.661647 \pm 1.120396 X$ & 0.30 & 120.00 & 0.057 \\
\hline & $1: 1$ & 0.079 & 0.053 & 0.120 & $Y=4.087872 \pm 1.013522 X$ & 1.11 & 28.72 & 0.144 \\
\hline & $1: 2$ & 0.140 & 0.096 & 0.205 & $Y=3.763572 \pm 1.077843 X$ & 0.44 & 24.41 & 0.081 \\
\hline \multirow[t]{5}{*}{ PM:Cl } & $1: 5$ & 0.327 & 0.207 & 0.515 & $Y=4.543817 \pm 0.8873508 X$ & 1.44 & 20.96 & 0.035 \\
\hline & 1:10 & 0.241 & 0.124 & 0.466 & $Y=4.680056 \pm 0.8396521 X$ & 0.29 & 52.06 & 0.047 \\
\hline & $1: 20$ & 0.294 & 0.192 & 0.448 & $Y=4.472741 \pm 1.127512 X$ & 0.07 & 82.01 & 0.039 \\
\hline & 1:1 & 0.077 & 0.051 & 0.116 & $Y=4.000392 \pm 1.125478 X$ & 1.43 & 29.53 & 0.148 \\
\hline & $1: 2$ & 0.086 & 0.060 & 0.124 & $Y=3.881017 \pm 1.195447 X$ & 0.02 & 39.72 & 0.132 \\
\hline \multirow[t]{3}{*}{ PM:CL } & $1: 5$ & 0.100 & 0.070 & 0.144 & $Y=3.762725 \pm 1.235348 X$ & 0.14 & 68.26 & 0.114 \\
\hline & 1:10 & 0.488 & 0.342 & 0.694 & $Y=3.912558 \pm 1.580527 X$ & 1.70 & 25.73 & 0.023 \\
\hline & $1: 20$ & 0.661 & 0.488 & 0.894 & $Y=3.354421 \pm 2.00696 X$ & 1.65 & 36.31 & 0.017 \\
\hline
\end{tabular}

$\overline{\mathrm{PM}}=$ Pirimiphos-methyl; $\overline{\mathrm{CA}}=$ Cardamom oil; $\mathrm{Cl}=$ Cinnamon oil; $\mathrm{CL}=$ Clove oil

In case of mixture of pirimiphos-methyl and cardamom oil the cotoxicity coefficient value has been calculated as $84.44,71.70,17.40,30.08$ and 120.00 at $1: 1,1: 2,1: 5,1: 10$ and $1: 20$ ratios respectively after $24 \mathrm{~h}$ of observation. The cotoxicity coefficient was also highest at 1:20 ratios suggesting the synergistic effect in this ratio. However, synergistic ratio was $0.422,0.239$, $0.029,0.027$ and 0.057 followed the order $1: 1>$ $1: 2>1: 20>1: 5>1: 10$. The cotoxicity coefficient of the mixture of pirimiphos-methyl and cinnamon oil in $1: 1,1: 2,1: 5,1: 10$ and $1: 20$ ratios has been calculated as 28.72, 24.41, 20.96, 52.06 and 82.01 respectively. Similarly the cotoxicity coefficient is highest at 1:20 ratio but no co- toxicity coefficient value was greater than 100, therefore with this oil no synergistic effect was significant. The synergistic ratio was $0.144,0.081$, $0.035,0.047$ and 0.039 follows the order $1: 1>1: 2$ $>1: 5>1: 10>1: 20$. For the mixture of pirimiphosmethyl and clove oil the cotoxicity coefficient values were $29.53,39.72,68.26,25.73$ and 36.31 at $1: 1,1: 2,1: 5,1: 10$ and 1:20 ratios respectively for 24 hours after treatment. The highest cotoxicity coefficient is at 1:5 ratio. The cotoxicity coefficient, however, did not exceed the mark 100 in any ratio. The synergistic ratio was $0.148,0.132$, $0.114,0.023$ and 0.017 in the above mentioned ratios of mixtures respectively. 

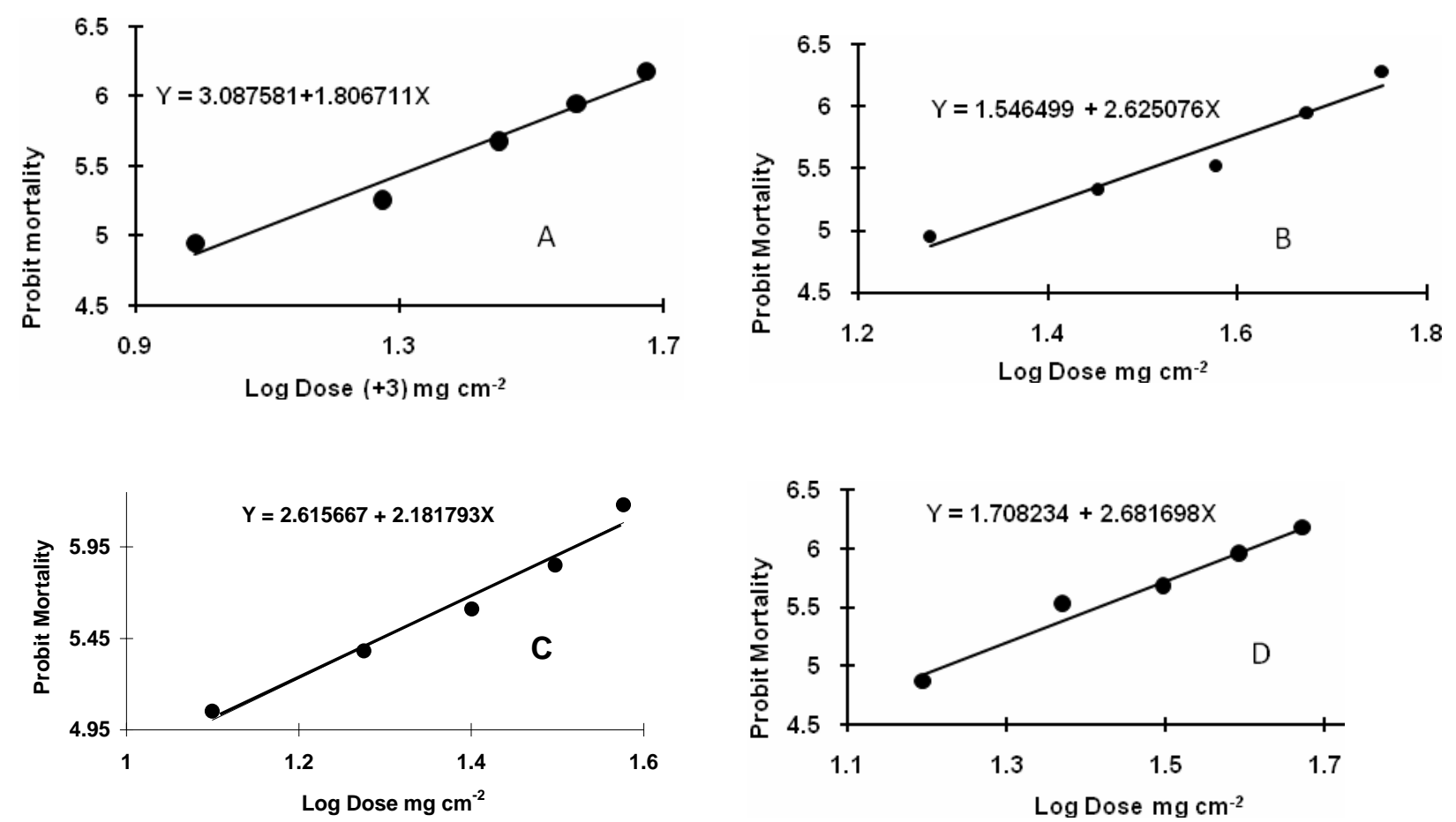

Fig. 1. Regression lines of log dose of pirimiphos-methyl (A), cardamom oil (B), cinnamon oil (C) and clove oil (D) on the probit mortality of adult C. maculatus after 24 hours of residual film treatment.

\section{Discussion}

Cinnamom oil was found to be highly effective in inducing mortality of C. maculatus. Clove and cardamom oils were also found to be effective as their $L_{50}$ values are very close. Pirimiphosmethyl also proved to be a good insecticide for control of C. maculatus. Swella \& Mushobozy (2007) evaluated the effectiveness to control C. maculatus in cowpea by the synthetic insecticide Actellic dust (pirimiphos-methl), and by natural protectants ash, coconut oil, powdered cloves and black pepper. Seeds treated with Actellic dust and black pepper powder had significantly low percentages of damaged seeds. There were differences in oil efficacy at the doses tested under different experimental conditions. The present results corroborates the findings of Jilani \& Malik (1973) who also reported the toxic effect of neem oil, coconut oil, rapeseed oil, mustard oil, sesame oil, dalda and palm oil on $C$. chinensis.

Cinnamaldehyde, the main constituent of cinnamon oil, exerted equal contact toxicity to both Tribolium castaneum and Sitophilus zeamais (Huang et al., 2000). Effect of three selected essential oils, viz. cardamom, cinnamon and clove oils on C. maculatus aduls evaluated in the present investigation exhibited that they induce mortality. Therefore, it was thought reasonable to study the combined action of these oils as synergist with pirimiphos-methyl. The results of the combined action revealed that the mixture of all three oil produced antagonistic effect in both 24 $\mathrm{h}$ after treatment. Only 1:20 ratio dose of pirimiphos-methyl showed some synergistic action having the co-toxicity coefficient value 120.00. The review of literature, however, revealed that no information is available on the combined action of mixture of essential oils for the control of C. maculatus and other stored grain pests. Kabeh \& Jalingo (2007) studied the insecticidal potency of dust from leaves of Vernonia amygdalina was compared with pirimiphos-methyl powder on the larvae of $C$. maculatus and $S$. zeamais and observed that both toxicants gave substantial control. Similar results have been reported by Rajapakse \& Rathnasekera (1998) who noted enhanced mortality and persistence of pirimiphosmethyl in causing significant mortality to C. maculatus and by Khalequzzaman and Chowdhury (2003) to $T$. castaneum when combined with vegetable oils. 


\section{References}

Abbott, W.S. 1925. A method of computing the effectiveness of an insecticide, J. Econ. Entomol. 18: $265-267$.

Ali, N.A.M. \& Jantan, I. 1999. Essential Oil of Cinnamomum Tahijanum Kost. from Sarawak. ASEAN Review of Biodiversity \& Environment Conservation (ARBEC. http://www.arbec.com.my /pdf/art5novdec99.pdf .4pp.

Asawalam, E.F. 2006. Insecticidal and repellent properties of Piper guineense seed oil extract for the control of maize weevil, Sitophilus zeamais. Electron. J. Environ. Agric. Food Chem. 5(3): 1389-1394.

Bauer, K., Garbe, D. \& Surburg, H. 2001. Common fragrance and flavor materials: Preparation, properties and uses. Wiley-VCH, Weinheim, 293 pp.

Braga, Y.F.B., Grangeiro, T.B., Freire, E.A., Lopes, H.L., Bezerra, J.N.S., Manoel Andrade-Neto, M. \& Lima, M.A.S. 2007. Insecticidal activity of 2tridecanone against the cowpea weevil Callosobruchus maculatus (Coleoptera: Bruchidae). An. Acad. Bras. Cienc. 79(1): 35-39.

Busvine, J.R. 1971. A critical review of the techniques for testing insecticides. Commonwealth Agricultural Buereux, London. pp. 345.

Caswell, G.H. 1981. Damage to stored cowpeas in Northern Nigeria. Samaru J. Agric. Res. 1: 1 l-19.

Chaubey, M.K. 2008. Fumigant toxicity of essential oils from some common spices against pulse beetle, Callosobruchus chinensis (Coleoptera: Bruchidae). J. Oleo Sci. 57(3): 171-179.

Finney, D.J. 1947. Probit analysis: a statistical treatment of the sigmoid response curve. Cambridge University Press. London. 333 pp.

García, M., Donadel, O.J., Ardanaz, C.E., Tonn, C.E. \& Sosa, M.E. 2005. Toxic and repellent effects of Baccharis salicifolia essential oil on Tribolium castaneum. Pest Manag. Sci. 61: 612-618.

Guenther, E. 1948. The Essential Oils. D. Van Nostrand, New York.

Huang, F. \& Subramanyam, B. 2005. Management of five stored-product insects in wheat with pirimiphosmethyl and pirimiphos-methyl plus synergized pyrethrins. Pest Manage. Sci. 61: 356-362.

Huang, Y., Chen, S.X. \& Ho, S.H. 2000. Bioactivities of methyl allyl disulfide and diallyl trisulfide from essential oil of garlic to two species of stored product pests, Sitophilus zeamais (Coleoptera: Curculionidae) and Tribolium castaneum (Coleopreta: Tenebrionidae). J. Econ. Entomol. 93: 537-543.

Jilani, G. and Malik, M.M. 1973. Studies on neem plant as repellent against stored grain insects. Pakistan J. Sci. Ind. Res. 16(6): 251-254.
Kabeh, J.D. \& Jalingo, M.G.D.S.S. 2007. Pesticidal effect of bitter leaf plant Vernonia amygdalina (Compositae) leaves and pirimiphos-methyl on larvae of Callosobruchus maculatus (Coleoptera: Bruchidae) and Sitophilus zeamais (Coleoptera: Curculionidae). Int. J. Agri. Biol. 9(3): 452-454.

Khalequzzaman, M. \& Chowdhury, F. D. 2003. Evaluation of mixtures of plant oils as synergists for pirimiphos-methyl in mixed formulations against Tribolium castaneum (Herbst). OnLine J. Bio. Sci. 2(3): 347-359.

Lee, B.H., Annisb, P.C., Tumaaliia, F \& Choi, W.S. 2004. Fumigant toxicity of essential oils from the Myrtaceae family and 1,8-cineole against 3 major stored grain insects. J. stored Prod. Res. 40: 553-564.

Ngamo, T.S.L., Ngatanko, I., Ngassoum, M.B., Mapongmestsem, P.M. \& Hance T. 2007. Persistence of insecticidal activities of crude essential oils of three aromatic plants towards four major stored product insect pests. Afr. J. Agric. Res. 2(4): 173-177.

Onuh, M.O. \& Onyenekwe, R.I. 2008. Assessment of inhibitory substances in the seed coat of some cowpea cultivars for resistance against Callosobruchus maculatus. Sci. World J. 3(2):15-19.

Park, K., Lee. S.G., Hoi, D.H., Park, J.D. \& Ahn, Y.J. 2003. Insecticidal activities of constituents identified in the essential oil from leaves of Chamaecyparis obtusa against Callosobruchus chinensis (L.) and Sitophilus oryzae (L.). J. stored Prod. Res. 39 (4): 375-384.

Prevett, P.F. 1961. Field infestation of cowpea (Vigna unguiculata) pods by beetles of the families Bruchidae and Curculionidae in Northern Nigeria. Bull. Entomol. Res. 52: 635-645.

Raja, M. \& William, S.J. 2008. Impact of volatile oils of plants against cowpea beetle Callosobruchus maculatus (Fab.) (Coleoptera: Bruchidae). Int. J. Integrated Biol. 2(1): 62-64.

Rajapakse, R. \& Rathnasekera, D. 1998. The effect of combining vegetables oil with pirimiphos methyl in the management of Callosobruchus maculatus in stored cowpea Vigna unguiculata L. Proc. 7th Int. working Conf. stored-product Prot. 1: 809-811.

Sun, Y.P. \& Johnson, E. R. 1960. Synergistic and antagonistic actions of insecticide-synergist combinations and their mode of action. J. Agric. Food Chem. 8: 261-266.

Swella, G.B. \& Mushobozy, D.M.K. 2007. Evaluation of the efficacy of protectants against cowpea bruchids (Callosobruchus maculatus (F.)) on cowpea seeds (Vigna unguiculata (L.) Walp.). Plant Protect. Sci., 43(2): 68-72.

USEPA 2003, Pirimiphos-methyl IRED facts; http://www.epa.gov/oppsrrd1/REDs/factsheets/ pirimiphosmethyl ired fs.htm. 